\title{
Atravessando pensamentos: diferença, différance, criança pequena e infância
}

\author{
Flávia Maria de Menezes* \\ Priscila de Oliveira Dornelles Machado**
}

\begin{abstract}
Resumo
O propósito deste ensaio é partilhar com os leitores interrogações e pensamentos acerca das muitas questões que afetam o debate contemporâneo sobre a educação da criança pequena no Brasil, a partir da ascensão das ideias de diversidade e diferença. Para tanto, levantamos alguns artigos que tratam de tais temáticas com ênfase nos discursos enunciados nas políticas públicas brasileiras para infância, como os de autoria de Rodrigues e Abramowicz (2013), Coppete, Fleuri \& Stoltz (2012), Abramowicz, Rodrigues e Cruz (2011), Abramowicz, Levcovitz e Rodrigues (2009), Abramowicz (2003), entre outros, em que pretendemos discorrer o debate, ancorando nossas proposições nas ideias de Jacques Derrida e seus leitores. No que tange às políticas públicas para as crianças e a infâncias no Brasil, optamos por dialogar com a legislação atual no que tange às diretrizes para organização do currículo nas creches e pré-escolas brasileiras.

Palavras-chave: educação infantil; infância; diversidade; diferença.
\end{abstract}

\section{Crossing thoughts: difference, differance, toddler and childhood}

\begin{abstract}
The purpose of this essay is to share with the readers' questions and thoughts about the many issues affecting the contemporary debate about the education of young children in Brazil, from the rise of diversity and difference of ideas. Therefore, we raise some articles dealing with such issues with emphasis on speeches set out in Brazilian public policies to childhood, as written by Rodrigues and Abramowicz (2013), Coppete, Fleuri \& Stoltz (2012), Abramowicz, Rodrigues and Cruz (2011), Abramowicz, Levcovitz and Rodrigues (2009), Abramowicz (2003), among others, in which we intend to discuss the debate, anchoring our propositions on Jacques Derrida's ideas and their readers. With regard to public policies for children and childhood in Brazil, we opted for dialogue with the current legislation regarding the guidelines for the organization of the curriculum in Brazilian kindergartens and preschools.

Keywords: childhood education; childhood; diversity; difference.
\end{abstract}

Se a diversidade cultural é uma categoria da ética, da estética ou da etnologia comparativas, a diferença cultural é um processo de significação através do qual enunciados sobre ou em uma cultura diferenciam, discriminam e autorizam a produção de campos de força, referência, aplicabilidade e capacidade.

Homi Bhabha, 1994.

\section{Introdução}

O presente ensaio é fruto dos pensamentos e traduções produzidos nas e pelas leituras e discussões realizadas nos encontros do Grupo de Pesquisa Infância e Saber Docente, coordenado pela Prof $^{a}$ Dra. Ligia Maria M. L. de Aquino, no programa de Pós-Graduação em Educação PROPED, da Universidade do Estado do Rio de Janeiro (UERJ), do qual somos pesquisadoras cursando o Mestrado em Educação, assim como na disciplina eletiva do curso de Mestrado em Educação Perspectivas da Diferença e Pesquisa em Educação, ministrada pelas professoras Maria da Conceição Silva Soares e Mirian Leite, da qual uma das autoras deste ensaio participou como aluna regular do referido curso.

$\mathrm{O}$ grupo de pesquisa em questão coloca na centralidade de seus estudos e discussões as temáticas da criança e da infância, assim como os mais diversos contextos nos quais e pelos quais emergem tais temáticas. No decorrer dos estudos e debates, fomos sendo provocadas a pensar sobre o quão escorregadio são os sentidos que a ideia da diversidade confere aos discursos que enunciam a infância no debate contemporâneo brasileiro sobre a educação da criança pequena.

Segundo Rodrigues e Abramowicz (2013), a partir da década de 1990 a diversidade, seus temas e contextos vêm sendo tratados com centralidade no

*Professora de Educação Básica Técnica e Tecnológica (EBTT) do Colégio Pedro II campus São Cristóvão I. Endereço eletrônico: flaviamaria37@yahoo.com.br

*** Professora de Educação Básica Técnica e Tecnológica (EBTT) do Colégio Pedro II campus São Cristóvão I. Endereço eletrônico: pridornelles@hotmail.com 
cenário das políticas públicas, principalmente na área da educação. No mesmo sentido os estudos de Coppete, Fleuri \& Stoltz (2012) apontam que o discurso da diversidade "vem se constituindo como um dos principais fatores para dar visibilidade" às crianças principalmente nos "contextos educacionais" (p. 17) brasileiros e salientam para a importância do entendimento da diversidade como uma categoria política que não deve estar desvinculada das lutas históricas e dos movimentos sociais (COPPETE; FLEURI; STOLTZ, 2012, p. 233). Nessa perspectiva, é possível perceber que os estudos referidos, principalmente os últimos, consideram que a expressão diversidade, neste contexto, representa o caminho das relações sociais, colocando em questão importantes segmentos dos movimentos sociais que debatem sobre gênero, discriminação racial, criança com deficiência, entre outros temas geradores de tensão na sociedade.

Cabe colocar, ainda segundo Coppete, Fleuri \& Stoltz (2012), que é possível encontrar uma variedade de sentidos para o conceito de diversidade e que tais sentidos são bastante complexos. Nas ciências sociais, por exemplo, este conceito foi amplamente utilizado pelos pensadores dos estudos culturais e pós-coloniais como contraposição ao discurso da homogeneidade defendido pelo modelo de Estado-nação moderno, liberal e ocidental.

Essa posição se contrapõe ao modelo de Estado-nação moderno, liberal e ocidental, constituido "[...] sobre o pressuposto (geralmente tácito) da homogeneidade cultural organizada em torno de valores universais, seculares e individuais" (HALL, 2003 apud COPPETE; FLEURI; STOLTZ, 2012, p. 233) $)^{1}$.

Os estudos culturais e pós-coloniais, que defendem o direito de todos os seres humanos à dignidade, à solidariedade e ao respeito, em diálogo com as "políticas de diferença" motivaram a luta de novos grupos sociais pela afirmação identitária e a negação da condição de subalternidade as quais esses grupos estiveram assujeitados. Os referidos autores fazem uma ressalva ao contexto brasileiro, identificando neste processo o movimento feminista e o movimento negro, nos anos de 1980; o movimento indígena e o movimento das pessoas com deficiência nos anos 1990 e 2000
(ABRAMOWICZ; RODRIGUES; CRUZ, 2011, p. 90).

Assim, a preocupação com a diversidade cultural brasileira, principalmente no tocante às questões de gênero, raça e etnia começa, a partir dos anos de 1990, a ganhar maior visibilidade nas políticas públicas sociais, principalmente no campo da educação, no sentido de orientar a ação dos professores e professoras para um trabalho que pudesse superar as desigualdades sociais, na perspectiva de que este problema se constitui "pelos pertencimentos culturais" e seria um dos maiores causadores dos "desempenhos desiguais" e da exclusão escolar (Idem). Coppete, Fleuri \& Stoltz (2012) citam evidências desta preocupação nas políticas públicas educacionais do final dos anos de 1990 e início dos anos de 2000:

(...) a incorporação da pluralidade cultural como tema transversal nos Parâmetros Curriculares Nacionais; a definição de um capítulo específico para abordar a educação especial; assim como os artigos voltados à educação indígena na Lei de Diretrizes e Bases da Educação Nacional LDB - n. 9.394/96; o Plano Nacional de Educação de 2001, com capítulos destinados à educação especial e educação indígena; a definição do dia 20 de novembro como dia da Consciência Negra; além das leis Lei n. 10.639/03 e Lei $n$. 11.645/08 (...) (COPPETE; FLEURI; STOLTZ, 2012, p. 235).

Nesse sentido, a escola torna-se a arena onde os conflitos, debates e soluções para o enfrentamento das desigualdades culturais e sociais, principalmente a econômica, serão tratados fundamentados na cultura como um princípio educativo e na diversidade cultural como um tema transversal na organização dos currículos escolares. Entretanto, neste debate é possível perceber que os conceitos de diversidade e diferença são tratados como semelhantes e complementares, desconsiderando o fato de que tais ideias não são iguais e nem tampouco se aproximam, uma vez que a diversidade nesta perspectiva parece reconhecer as culturas como diferenciadas, porém um ato de diferenciação baseado em hierarquias e classificações, como por exemplo: os negros, os índios, as mulheres, as crianças, os deficientes e outras formas de classificação. Uma espécie de diferença sem conflitos e aprisionada na própria 
diferença, sem o reconhecimento de que as diferenciações também produzem diferenças. Sobre isto, consideramos os argumentos de Rodrigues e Abramowicz:

(...) a imprecisão ou seu uso indiscriminado (o conceito de diversidade $)^{4}$ pode restringir-se ao simples elogio às diferenças, pluralidades e diversidades, tornando-se uma armadilha conceitual $e$ uma estratégia política de esvaziamento elou apaziguamento das diferenças e das desigualdades

(RODRIGUES; ABRAMOWICZ, 2013, p. 17).

Portanto, temos aí um aspecto bastante escorregadio no discurso da diversidade que, ao invés de afirmar a diferença, como se propõe, promove $o$ seu apagamento, disfarçando a desigualdade e a discriminação na proposta da tolerância, da igualdade de direitos e da suposta dignidade social, anunciadas nos discursos como ideias universais, estáveis e harmônicas, suficientemente capazes de desestabilizar os conflitos, as lutas e o desmascaramento da vida concreta para os sujeitos.

Considerando esta análise de maneira simplificada e inicial é possível identificar nestas matrizes que a diversidade tem um caráter universal, pois é uma síntese que totaliza as diferenças, ou seja, as diferenças $e$ as diversidades se configuram como cultura que, por esta via, podem então ser trocadas. Uma das problemáticas decorrentes é que a cultura acaba perdendo sua matriz singular e torna-se um conceito universal, como o biológico (ABRAMOWICZ; RODRIGUES; CRUZ, 2011, p. 92).

Poderíamos arriscar dizer que a proposta de uma educação pautada na diversidade cultural é direcionada, basicamente, para determinados grupos da sociedade cujos direitos sociais vêm sendo negados ou desconsiderados por longo tempo, numa espécie de pagamento de uma dívida para que tais grupos e indivíduos se reconheçam como pertencentes a sua cultura. E é aí que "a coisa escorrega", pois o reconhecimento da existência de diversas culturas está amparado na tolerância de algumas culturas, grupos e indivíduos para com outros e outras, o que, segundo Abramowicz,
Rodrigues e Cruz, "significa manter intactas as hierarquias do que é considerado hegemônico" (Idem, p. 91). Além disso, as autoras ainda salientam o fato de que o discurso da diversidade, para além da educação escolar e das políticas sociais, penetrou em outros campos da vida pública e privada, atingindo as "subjetividades antes intactas", com a intenção de alargar o campo do capital, formando públicos e mentalidades, como a boneca negra, o seguro de automóvel destinado à mulher, o horário de programação na mídia televisiva específica para as crianças, por exemplo.

Portanto, nesses "escorregamentos" outros tantos termos e ideias vinculadas à diversidade cultural foram emergindo como alternativa para buscar o que é comum entre as culturas, como o multicultruralismo, o transcultural, o pluricultural e o intercultural, que na verdade circundam em torno de uma mesma ideia: o apaziguamento das relações sociais, neutralizando as diferenças para que elas não façam o que de fato deveriam fazer: diferir.

Poderíamos colocar muitos outros pensamentos que nos provocaram para ampliar o debate, entretanto estaríamos extrapolando os limites deste texto. Inclusive, também por conta desses limites, optamos por não contemplar as especificidades que diferenciam o debate sobre a diversidade nas diversas sociedades onde os conflitos e mobilizações sobre as identidades culturais emergiram. Nesse sentido, sugerimos a leitura do estudo de Abramowicz, Rodrigues e Cruz (2011), assim como os autores que trouxemos em diálogo nessa discussão.

No referido estudo, as autoras sinalizam três vertentes perceptíveis, por onde caminham os debates, traduções e conceituações sobre as temáticas da diversidade e da diferença. Uma primeira vertente está pautada no fato de que tais ideias, apesar de contraditórias, circundam em campos semânticos semelhantes. Neste caso, o argumento para o diálogo seria o apaziguamento das contradições através da tolerância e da negociação das diferenças. Abramowicz, Rodrigues e Cruz sublinham, neste contexto, a finalidade do multiculturalismo educacional como possibilidade (ilusória) para esta "repactuação sem esgarçar o tecido social" (p. 91). Uma segunda vertente possível, seria, como já colocado anteriormente, a "ampliação das fronteiras do capital" produzindo novas subjetividades a partir das ideias da diferença e da diversidade. As autoras afirmam que esta vertente está ancorada nas ideologias do liberalismo e do neoliberalismo. A terceira vertente possível, e 
com esta pretendemos dialogar neste ensaio, é defendida pelos estudos pós-estruturalistas, pautada nas diferenças como produtoras de diferenças, em que o apaziguamento não se justifica uma vez que não há contradições, pois, de acordo com Soares ${ }^{5}$, "a diferença é um ser, um pensamento", com sentido em si mesma, portanto, nesta trama, não há o que trocar e nem o que negociar.

\section{Entrando no debate - Atravessando pensamentos: diferença, différance, criança pequena e infância}

Partindo das discussões anteriores, nossa proposta agora é trazer algumas perspectivas teóricas que podem equacionar este debate ou pelo menos produzir efeitos de sentidos menos escorregadios para a questão das crianças e da infância no contexto educacional, que é o foco nas discussões que propomos neste ensaio.

Pensando a infância na vertente da diferença como produtora de diferenças, podemos arriscar dizer que este conceito (infância) já nasceu inadequado, pois afirmar que as crianças são sujeitos de direitos e produtores de cultura e a infância um conceito constituído na e pela história, não garante o reconhecimento das diferenças entre as populações infantis, ou melhor dizendo, os diferentes modos de nascer e de experimentar sensações, de afetar e ser afetada nas experiências da criança com/no mundo, os modos de apropriação de si mesma, entre outras situações. Quando enunciam que o bebê é socialmente ativo e interativo, disfarçadas por trás da "inter- ação" estão as interpretações dos adultos sobre as ações dos bebês, ou seja, é a partir do adulto que se conhece as possibilidades de interação dos bebês, já que eles próprios não têm como traduzi-las. Entretanto, ainda que os discursos afirmem haver crianças e infâncias diferentes, esta afirmação da diferença não garante a alteridade para com a infância e as singularidades das crianças, já que neste contexto podemos considerar uma ideia de diferença estável e universal, e, portanto, encarnada no sujeito, nos grupos e nas culturas tidas como diferentes. Uma espécie de contorno ou fronteira que separa e identifica tais sujeitos, grupos e culturas dos demais pelas suas diferenças, mas não as identifica.

A hipótese da différance defendida por Jacques Derrida pareceu-nos uma possibilidade para pensarmos a diferença e não produzi-la com um sentido escorregadio. Bingham (2013), pensando Derrida, nos diz que a relação significado e significante não é intrínseca e nem tampouco imutável, mas "tumultuosa", pois, "quando um significado está em posição de atribuir sentido, ele defere o sentido mesmo que ele deveria dar" ( $p$. 416), ou melhor dizendo, mais do que simplesmente conferir sentido, o significado é uma possibilidade para o significante, tornando-o potente. Bingham coloca ainda que, um pensamento, proferido ou não, é pertinente a "um contexto específico, em um tempo específico, com referência a uma série de circunstâncias específicas", o que the permite conferir, deferir e diferir sentidos, já que a especificidade dos contextos confere diferenciações em sentidos na relação significante e significado (Idem). Como exemplo, quando enunciamos "criança negra" em relação a uma criança, ao mesmo tempo em que fazemos referência a uma etnia, conferindo um sentido para negro, outorgamos um sentido de ser negro para uma determinada criança na qual estamos nos referindo; da mesma forma como o sentido da "pele preta" para as crianças negras brasileiras difere em relação à criança negra nigeriana, por exemplo, e essas possibilidades de tradução transparecem em nossos discursos ainda que não tenhamos a intenção e a consciência disto.

Nesse diálogo, Bingham vai mostrando em Derrida que a linguagem difere e defere, num "movimento duplo e escorregadio", mas um "escorregamento" potente em sentidos, ou seja, pensar a diferença na leitura da différance é pensála como potência que explode como possibilidade de deslocamento em direção ao outro, na sua captura $^{6}$. Nas palavras de Derrida (2004):

$O$ que o motivo da différance tem de universalizável em vista das diferenças é que ele permite pensar o processo de diferenciação para além de qualquer espécie de limites: quer se trate de limites culturais, nacionais, linguísticos ou mesmo humanos. Existe a différance desde que exista traço vivo, uma relação vida/morte ou presença/ausência. (...) Existe a différance desde que haja o vivo, desde que haja o traço, através e apesar de todos os limites que a mais forte tradição filosófica ou cultural acreditou reconhecer entre o "homem" e o "animal". Há portanto ai claramente uma potência de universalização. Depois a différance não é uma distinção, uma essência ou uma oposição, mas um movimento de 
espaçamento, um "devir-espaço" do tempo, um "devir-tempo" do espaço, uma referência à alteridade, a uma heterogeneidade que não é primordialmente oposicional. Daí uma certa inscrição do mesmo, que não é o idêntico, como différance (...) (p. 34).

Portanto, a diferença pela différance é incomensurável e nos coloca em ato de hesitação, o que é uma condição muito difícil uma vez que a linguagem, como um dispositivo de poder, é quase sempre hegemônica e determinante, pois exerce grande força para que tudo esteja posicionado no seu devido lugar: as ideias, as ideologias, os sentidos ${ }^{7}$. É preciso, então, desconstruir as lógicas que engendram as verdades nos processos de assujeitamento e subjetivação que interpelam os processos de individuação e socialização dos sujeitos, grupos e culturas.

Sem direito aos atos de hesitação, a infância vem sendo reelaborada no tempo-espaço como um "bolsão de sentidos que se sobrepõe a todas as crianças"; um forte dispositivo que atua de "forma capilar" sobre as crianças, sem que elas possam pensar por si só sobre elas mesmas (ABRAMOWICZ; LEVCITZ; RODRIGUES, 2009, p. 193). Sobre isso, propomos algumas interpelações nas narrativas legais que orientam a infância nas instituições de educação infantil:

Educação Infantil: Primeira etapa da educação básica, oferecida em creches $e$ pré-escolas, às quais se caracterizam como espaços institucionais não domésticos que constituem estabelecimentos educacionais públicos ou privados que educam e cuidam de crianças de 0 a 5 anos de idade no período diurno, em jornada integral ou parcial, regulados e supervisionados por órgão competente do sistema de ensino $e$ submetidos a controle social ${ }^{8}$.

As Diretrizes Curriculares Nacionais para a Educação Infantil (DCNEI) representam o "compromisso" do poder público e da sociedade para com a educação da infância brasileira. Dizemos isso, porque este documento especificamente vai tratar das propostas pedagógicas, sua criação, implementação e avaliação nas instituições de educação infantil, que, pela atual legislação, compreendem as creches e pré-escolas. Portanto, um dispositivo social traduzido em cerca de 40 páginas, que tem a pretensão de regular as experiências de todas as crianças brasileiras no interior dos espaços formais de educação. Podemos observar alguns "escorregamentos" (nada potentes, na nossa opinião) já neste primeiro trecho que destacamos do documento: a educação infantil é uma etapa de um processo mais duradouro que se estabelece na nossa sociedade. O que nos leva a pensar que a educação da criança tem seus limites colocados nestes territórios de educação infantil "recomendados" e controlados pelos adultos. $\mathrm{O}$ que pensar das crianças de 6 aos 11 anos: não são crianças? Não são infantis? Como ficam suas experiências?

Outra questão é a atenção que o documento coloca na caracterização que confere a tais espaços, entendendo como aqueles que se diferenciam dos espaços domésticos, ou seja, não são iguais as casas das crianças e, portanto, esses corpos e mentes que serão educados nos territórios de educação infantil são deslocados de um espaço para o outro, passando da situação de criança, em casa, para aluno/educando/estudante na escola, e nesse bojo vão os desejos, os hábitos, as regras, as condições e toda uma cultura que, uma vez doméstica, torna-se frágil no enredo de intenções que é criado para educar as crianças nessas instituições: casa é casa, escola é escola, e a criança, o que é?

Uma última questão que destacamos é o controle explícito dessas instituições pelos adultos que são os responsáveis por definir o que é e $o$ que não é pertinente nos territórios de educação infantil, já que deverão ser "regulados e supervisionados por órgão competente do sistema de ensino e submetidos a controle social", sem deixar claro o papel da criança nas escolhassobre a sua própria educação.

Sobre as crianças, a condição de "sujeito histórico e de direitos" é colocada superficialmente no documento, já que não há qualquer referência aos fundamentos filosófico-políticos em que esta condição está amparada neste documento, e nem tampouco uma tradução mais específica das pessoas responsáveis pela sua elaboração sobre o que significa ser "sujeito histórico e de direitos" numa sociedade como a nossa:

Criança: Sujeito histórico e de direitos que, nas interações, relações e práticas cotidianas que vivencia, constrói sua identidade pessoal e coletiva, brinca, imagina, fantasia, deseja, aprende, observa, experimenta, narra, questiona e constrói 
sentidos sobre a natureza e a sociedade, produzindo cultura'.

Portanto, ficam para nós as seguintes interrogações: ser "sujeito histórico e de direitos" é uma condição? Uma marca identitária? É um traço cultural? É a expressão da diversidade cultural brasileira? De qual história as crianças estão sujeitas: as suas? As histórias do Brasil? A história dos vencedores ou a dos vencidos? $\mathrm{E}$ os seus direitos, onde estão prescritos? Nas leis? Nas suas necessidades? Nas ausências e desigualdades nas quais se assujeitaa maioria da população infantil brasileira?

Currículo: Conjunto de práticas que buscam articular as experiências e os saberes das crianças com os conhecimentos que fazem parte do patrimônio cultural, artístico, ambiental, científico $e$ tecnológico, de modo a promover o desenvolvimento integral de crianças de 0 a 5 anos de idade.

\section{Proposta Pedagógica: Proposta pedagógica ou projeto político pedagógico é o plano orientador das ações da instituição e define as metas que se pretende para a aprendizagem $e \quad o$ desenvolvimento das crianças que nela são educados e cuidados. É elaborado num processo coletivo, com a participação da direção, dos professores e da comunidade escolar $^{10}$.}

Quanto às experiências infantis, o documento define "currículo" e "proposta pedagógica" como duas coisas distintas, apesar de não explicitar diferenças quanto à finalidade e quanto ao significado, já que ambos dizem respeito às experiências que se vinculam às crianças nessas instituições. Com relação à proposta pedagógica, fica explícito que neste instrumento as intenções educativas (por onde passam a infância, a educação das crianças, suas experiências, vivências e necessidades e, certamente, o projeto de sociedade que se pretende constituir) serão traduzidas (idealizadas) pela direção da instituição, os professores e a comunidade escolar, sem distinção de quem e com qual papel neste processo. Mais uma vez as crianças foram apagadas, pois o documento não deixa transparecer as condições em que as crianças poderão pensar por si só e sobre elas mesmas. Além disso, pelo documento, as crianças, para aprenderem e se desenvolverem integralmente, devem brincar, imaginar, fantasiar, desejar, observar, experimentar (tudo?!), narrar, construir sentidos sobre a natureza e sociedade, entre outras ações que nos permitiram pensar sobre as reais vivências e experiências das crianças. Portanto, elas não sofrem, não sentem medo, não se conflituam, não disputam, não exercem poder umas sobre as outras, não discriminam, ou pelos menos essas ações não devem ser entendidas como experiências com sentido de aprendizagem para as crianças e nem tampouco devem ser consideradas como pertinentes aos espaços institucionais. Talvez sentir medo, fome, frio, solidão, raiva, perda, indiferença, preconceito são questões que dizem respeito às experiências "domésticas" e, portanto, distintas daquelas que serão vividas na escola. São acontecimentos "específicos" e singulares, daí pertencerem à criança e não à escola, seu currículo e sua proposta pedagógica. Talvez, também, esteja subentendido que essas experiências não são infantis, não pertencem ao "ser criança" e não fazem parte da infância. Sofrer não é coisa da infância, nem perder, nem sentir solidão, nem ter raiva, nem disputar espaço, nem exercer poder sobre... etc.

Vejam quantos sentidos escorregam nas tramas deste discurso que pretende representar o "direito social das crianças", fazendo valer o compromisso firmado na Carta Magna do país para com a sua sociedade ${ }^{11}$. Vejam, também, quantas fixações que se estabelecem para as crianças e para a infância neste contexto de educação, e vamos citar algumas: não há como pensar a infância sem a brincadeira na forma como a escola a define, portanto a criança que não brinca "essa brincadeira" não tem infância e não aprende; o exterior da criança se traduz pela imaginação e pela fantasia, logo existe uma fronteira entre o imaginário e o fantasioso e a realidade, que neste caso é uma realidade fixada pelo adulto, que não faz parte da infância, colocando, assim, mais uma fixação: realidade é coisa de adultos e fantasia é coisa de criança.

Em diálogo com Leite ${ }^{12}$, vamos pensando nas fixações que se estabelecem para a infância e para as crianças. A grande questão da fixação é que ela estabiliza a ideia, impossibilitando o deslizamento e os deslocamentos de sentidos, ou o que colocamos anteriormente como "escorregamentos potentes". Quando dizemos que a brincadeira está posta para a infância como uma fixação, devemos levar em consideração que Leite, 
em suas conversas, orientou para o fato de que há fixações necessárias e positivas, o que é considerável em relação às crianças e às infâncias. Voltando à questão dos bebês na sua dependência biológica dos adultos, podemos dizer que, ao longo do tempo, as crianças vêm conseguindo cada vez mais persuadir os adultos a estreitar o tempo-espaço desta dependência, mas não há como negar que ela existe e que em certos contextos é necessária. Portanto, ainda seguindo no fio que Leite nos deixou, a fixação é social e precisa ser o tempo todo problematizada nos nossos discursos, mas há indícios de positividade e necessidade orientando as fixações, como no caso da brincadeira, por exemplo, e precisamos estar atentos para capturar o que não foi fixado e teve seu sentido apagado. Como exemplo, citamos as crianças que brincam com o lixo enquanto trabalham com seus pais catadores nos lixões da cidade; de fato estão brincando e produzindo sentidos, mas como ficam esses sentidos para os currículos, as propostas pedagógicas e os profissionais nas instituições de educação infantil, principalmente quando estes tratam o lixo, que é o brinquedo para esta criança e o "ganha pão" para a sua família, como algo que não tem valor, que prejudica a saúde, que polui o ambiente?

Contudo, apesar da necessidade de ampliar esta discussão, não o faremos no presente debate, pois nos levaria a muitos desvios. Entretanto, atravessando pensamentos na diferença em différance, a infância e as práticas culturais infantis não estão condicionadas e nem tampouco limitadas aos territórios "recomendados ou mesmo 'autorizados' pelos adultos", pois ao contrário do que enunciam os discursos, quando as crianças começam a apontar que participam da sociedade, na sua complexidade, vivem o mundo na cultura em que participam,

[...] sem operar com essa linha divisória e, via de regra, nutrem especial interesse justamente por aquilo que escapa aos padrões educativos, protetivos, prescritos pela ótica do adulto. Assumir essa perspectiva de visada, vale frisar, não implica em esvaziar o lugar do adulto na responsabilidade com a educação, o cuidado e o respeito com as crianças. $O$ que está em jogo é a construção de um outro lugar social a partir do qual se torne possível dialogar com as crianças relativizando a hierarquia cristalizada pela modernidade (RIBES PEREIRA, 2014, $s / p)^{13}$.

Nesse sentido, é preciso inverter a lógica do educar para atuar como adulto e esperar da infância as "instruções" necessárias ${ }^{14}$ à educação das crianças, aberta à experiência enquanto abertura à diferença. A experiência, nesse sentido, é algo que "nos passa, nos toca e nos atravessa", nos submete ao risco e ao perigo, mas nos possibilita a nossa própria transformação. Entretanto, experiência não se refere somente ao ato de experimentar algo novo, de viver uma nova situação; o sujeito que vive a experiência não passa apenas por ela, e sim por ela é afetado. A experiência é sempre uma "possibilidade de que algo nos aconteça", não há como prever o acontecimento da experiência e, portanto, não há como ter controle, conhecimento e poder sobre ela; a experiência não está em função da nossa vontade, mas é preciso que estejamos abertos e sensíveis às nossas experiências; que paremos para pensar, para olhar, escutar com mais atenção, observar com detalhes; requer reflexão, um "gesto de interrupção", uma entrega sensível e, portanto, um risco (LARROSA, 2005, p. 25-26).

Ao pensarmos a infância relacionada à experiência podemos compreendê-la como um território de passagem. Não uma passagem que se dá em um tempo "linear, gradativo e cumulativo", vinculado às idades das crianças, mas, como ressalta Abramowicz, Levcovitz e Rodrigues, uma passagem que se dá numa "temporalidade múltipla" (2009, p. 180).

Nas muitas leituras que fizemos para a escrita deste ensaio, encontramos em Benjamin alguns pensamentos com os quais desejamos concluir o nosso. Um deles é a geniosa alegoria do labirinto com a qual Benjamin abre uma das passagens de seus escritos em "Infância em Berlim por volta de 1900": Saber orientar-se numa cidade não significa muito. No entanto, perder-se na cidade, como alguém se perde numa floresta, requer instrução(BENJAMIN, 1987, p. 73). Vejam, que Benjamin inverte a lógica ao escrever que para perder-se... requer instrução. A mesma inversão provocada por Abramowicz, ao pronunciar que a instrução vem da infância, assim como a mesma inversão proposta por Larrosa ao pensar a experiência como um risco que ensina. Pensamos essa inversão como um deslocamento em direção à desconstrução da infância como um território colonizado pelo adulto.

O labirinto benjaminiano traduzido na e 
pela experiência da infância nos possibilita entrar no jogo do perder-se e achar-se com as crianças, e com elas criar e recriar, potencializar a vida. Nas palavras de Abramowicz, Levcovitz e Rodrigues, é preciso encontrar com a infância, seja na escola, seja na pesquisa, como um devir,

[...] devir não como um vir a ser, pois já vimos que não tem nada a ver com o futuro, com uma cronologia qualquer, mas, sim, com aquilo que somos capazes de produzir $e$ de inventar como possibilidade de vida. Pois o espaço de criação também deve ser produzido, numa espécie de produção do espaço de criar (2009, p. 195).

\section{Referências}

ABRAMOWICZ, Anete; LEVCOVITZ, Diana; RODRIGUES, Tatiane Cosentino. Infâncias em Educação Infantil. Pro-Posições, Campinas, v. 20, n. 3 (60), set./dez. 2009, p. 179-197.

; RODRIGUES, Tatiane Cosentino; CRUZ, Ana Cristina Juvenal da. A diferença e a diversidade na educação. Contemporânea - Revista de Sociologia da UFSCar. São Carlos, Departamento e Programa de Pós-Graduação em Sociologia da UFSCar, n. 2. p. 85-97. 2011.
BENJAMIN, Walter. Obras Escolhidas. Volume 2. Rua de Mão Única. Tradução Rubens Rodrigues Torres Filho e José Carlos Martins Barbosa. São Paulo: Brasilense, 1987.

BINGHAM, Charles. Derrida e o ato de ensinar:a economia do apagamento. Tradução de Jason Carreiro. Sapere Aude, Belo Horizonte, n. 7, v. 4, 2013, p. 413-440.

COPPETE, Maria Conceição; FLEURI, Reinaldo Matias; STOLTZ, Tânia. Educação para diversidade numa perspectiva intercultural. Revista Pedagógica - UNOCHAPECÓ - Ano-15 - n. 28 vol. 01 - jan./jun. 2012.

DERRIDA, J. De que amanhã: diálogo/ Jacques Derrida; Elisabeth Roudinesco. Trad. André Telles; revisão técnica Antonio Carlos dos Santos. Rio de Janeiro: Zahar Ed., 2004, p. 34.

LARROSA, Jorge Bondía. Tradução João Wanderley Geraldi. Notas sobre a experiência e o saber de experiência. Revista Brasileira de Educação, Rio de Janeiro, n. 19, jan/fev/mar/abr 2002.

RODRIGUES, Tatiane Consentino; ABRAMOWICZ, Anete. O debate contemporâneo sobre a diversidade e a diferença nas políticas e pesquisas em educação. Educação e Pesquisa, São Paulo, v. 39, n 1, jan./mar. 2013, p. 15-35.

\section{Sobre as autoras}

Flávia Maria de Menezes é graduada em pedagogia pela Universidade do Estado do Rio de Janeiro (UERJ); mestre em Educação pela UERJ; professora de Educação Básica Técnica e Tecnológica (EBTT) do Colégio Pedro II campus São Cristóvão I.

Priscila de Oliveira Dornelles Machado é graduada em pedagogia pela Universidade do Estado do Rio de Janeiro (UERJ); cursando o mestrado em Educação na UERJ; professora de Educação Básica Técnica e Tecnológica (EBTT) do Colégio Pedro II campus São Cristóvão I.

Recebido em maio de 2015.

Aprovado em setembro de 2015. 